\title{
Effects of Aldosterone and Atrial Natriuretic Peptide on Water and Electrolyte Homeostasis of Sick Neonates
}

\author{
TAKATSUGU KOJIMA, YUKA FUKUDA, YUKIO HIRATA, SHEUJI MATSUZAKI, AND \\ YOHNOSUKE KOBAYASHI \\ Department of Pediatrics, Kansai Medical University, Fumizonocho, Moriguchi, Osaka, Japan [T.K., Y.F., S.M., \\ Y.K.]; and Division of Hypertension, National Cardiovascular Center Fujishirodai, Suita, Osaka, Japan [Y.H.]
}

\begin{abstract}
To clarify fluid homeostasis in neonates, 27 sick neonates (51 had respiratory distress syndrome, 12 had hyperbilirubinemia, and nine were low birth wt infants) were studied on 13 to 15 days of age. The infants were stabilized and required neither ventilation nor intravenous fluids at the time of study. All infants were breast fed, and their sodium intake ranged from 1.7 to $2.9(2.2 \pm 0.3)$ $\mathrm{mEq} / \mathrm{kg} / \mathrm{d}$. Gestational age ranged from 30 to $39(34 \pm$ $3.4) w k$ and birth wt ranged from 1080 to $3280(2,070 \pm$ $672) \mathrm{g}$. Creatinine clearance (Ccr), fractional excretion of sodium (FENa), fluid and electrolyte balance, plasma aldosterone and human atrial natriuretic peptide (ANP) concentrations were determined and analyzed according to conceptional age (CA) to clarify their maturational changes. None of the infants had a negative sodium balance or hyponatremia. Ccr remained almost constant until the 36th wk of CA, after which an abrupt increase occurred. FENa and plasma aldosterone level of infants less than the $32 \mathrm{nd}$ wk of $\mathrm{CA}$ were high $(0.75 \pm 0.33 \%, 2868 \pm 1153 \mathrm{pg} /$ $\mathrm{ml}$, respectively) when compared with those in infants of the 33 to 34th wk of CA $(0.47 \pm 0.12 \%, 1,663, \pm 488 \mathrm{pg} /$ $\mathrm{ml}$, respectively). There was a negative correlation between FENa and plasma aldosterone level in all cases $(p<0.01)$. Plasma ANP level of all infants were higher than those of healthy adults $(40 \pm 20 \mathrm{pg} / \mathrm{ml})$. A good correlation was observed between Ccr and plasma ANP level in infants less than 36th wk of CA. These results show that the high plasma aldosterone concentrations possibly act to enhance the reabsorptive capacity of the distal nephron for sodium during development under conditions of low sodium intake and suggest that ANP may be released to control the extracellular space in premature infants with a limited Ccr. (Pediatr Res 25: 591-594, 1989)
\end{abstract}

\section{Abbreviations}

ANP, $\alpha$-human atrial natriuretic peptide

$\mathrm{CA}$, conceptional age

Ccr, creatinine clearance

$\mathrm{ECV}$, extracellular fluid volume

FENa, fractional excretion of sodium

GFR, glomerular filtration rate

LBW, low birth wt

RAAS, renin-angiotensin-aldosterone system

RDS, respiratory distress syndrome

Received October 18, 1988; accepted January 12, 1989.

Supported in part by Research Grants from the Morinaga Hoshikai, Katanosho of Kansai Medical University and the Mami Mizutani Foundation.

Correspondence Takatsugu Kojima, M.D., Department of Pediatrics, Kansai Medical University, Fumizonocho 1, Moriguchi, Osaka 570, Japan.
Plasma aldosterone concentration is relatively high in human newborn infants $(1,2)$. The cause of increased activity of the RAAS during the neonatal period is not clear. In the newborn the homeostatic function of the kidney may be limited (3). Although full-term infants are able to maintain the volume of body fluids within a narrow range, the physiologic limitations of the renal control of salt and water balance in low birth wt infants are not well established. In addition, recent reports demonstrated that ANP may play an important part in regulating water balance in the newborn period $(4,5)$. The purpose of this study was to clarify the roles of RAAS and ANP in neonatal fluid homeostasis.

\section{MATERIALS AND METHODS}

Study protocol. A total of 27 hospitalized sick neonates (15 boys and 12 girls; six had RDS, 12 had hyperbilirubinemia, and nine were LBW infants) were the subjects of this study. Informed consent was obtained from each patient's parents. Gestational age ranged from 30 to $39(34 \pm 3.4)$ wk and birth wt ranged from 1080 to $3280(2,070 \pm 672) \mathrm{g}$. These 27 infants were divided into five groups according to the CA: group A, 5 infants of 30 to $32 \mathrm{wk}$; group B, 6 infants of 33 to $34 \mathrm{wks}$; group C, 6 infants of 35 to $36 \mathrm{wk}$; group D, 5 infants of 37 to $38 \mathrm{wk}$; group E, 5 infants of 39 to 41 wk of CA, respectively. The CA was calculated by adding the postnatal age to the gestational age, judged from the mother's menstrual history and physical examination of the infants. Apgar scores of 1 and 5 min were $8.4 \pm$ 0.9 (range $7-10$ ) and $9.6 \pm 0.6$ (range $8-10$ ), respectively. Six infants with RDS were ventilated with the Bourns BP 2001 respirator. Duration of mechanical ventilation was $4.8 \pm 2.9$ (range 2-10) days. All infants had intravenous infusion therapy, which averaged $6.5 \pm 1.5$ (range 5-9) d in length. The infusion fluid consisted of $10 \%$ glucose supplemented with calcium $(100$ $\mathrm{mg} / \mathrm{kg} / \mathrm{d}$ ) within the first 3 days of life, after which sodium chloride $(35 \mathrm{mEq} /$ liter $)$ and potassium chloride $(20 \mathrm{mEq} / \mathrm{liter})$ were added. Total water intake $(\mathrm{ml} / \mathrm{kg} /$ day) during the $1 \mathrm{st}$ wk of life in the premature infants was determined by our study protocol: 50 to 60 on day 1,60 to 70 on day 2,70 to 80 on day 3 , and 100 to 120 on day 7 , respectively. The mean volume of fluid administered $(\mathrm{ml} / \mathrm{kg} /$ day) was $65 \pm 18$ on day $1,69 \pm 20$ on day $2,82 \pm 23$ on day 3 , and $120 \pm 26$ on day 7 , respectively. The sequential changes of body wt in infants of these five groups were shown in Table 1. None had bradycardia, hypotension, intracranial hemorrhage, or apnea in the early stages of life and clinical stability of the infants during the study period was good. All studies were performed at 13 to 15 days of life. All infants were breast fed. Sodium intake was determined by sodium analysis of the human milk sodium content (concentration ranged from $7-26 \mathrm{mEq} /$ liter: which averaged $15.4 \pm 2.2 \mathrm{mEq} /$ liter in premature and $13 \pm 2.4 \mathrm{mEq} /$ liter in mature infants' 
milk, (range 7-26 mEq/liter). No infants were placed on aminoglycosides or diuretics during the study period. None of the subjects had renal dysfunction. Mean serum creatinine concentration on the 7 th day of life was $0.76 \pm 0.13 \mathrm{mg} / \mathrm{dl}$ (range 0.5 to 1.0). Urine was collected in a collecting bag every $6 \mathrm{~h}$, once or twice during the study period. Blood sampling was done at the midpoint of urine collection.

Plasma and urine assay. Blood samples were collected between 0900 and $1200 \mathrm{~h}$ by puncture of the radial artery on the study day. Each specimen was collected in a syringe with sodium citrate as an anti-coagulant. Samples were centrifuged at $2000 \mathrm{rpm}$ for $10 \mathrm{~min}$ at $4^{\circ} \mathrm{C}$. Plasma was decanted to determine aldosterone, ANP, creatinine, and electrolytes. Each 6-h urine sample was pooled for the determination of sodium, potassium, and creatinine concentrations to calculate Ccr, FENa. Ccr and FENa were determined using standard formulas shown below:

$$
\begin{aligned}
\mathrm{CCr}(\mathrm{ml} / \mathrm{min} / \mathrm{kg})=\frac{\mathrm{Ucr} \times \mathrm{V}}{\mathrm{Scr}}, \quad \text { FENa }(\%) & \\
& =\frac{\mathrm{UNa} \times \mathrm{SNa}}{\mathrm{Ucr} \times \mathrm{Scr}} \times 100,
\end{aligned}
$$

where SNa indicates serum sodium concentration (mEq/liter); $\mathrm{V}$, urine flow $(\mathrm{ml} / \mathrm{min} / \mathrm{kg})$; UNa, urinary sodium concentration (mEq/liter); Scr, serum creatinine $(\mathrm{mg} / \mathrm{dl})$; Ucr, urinary creatinine $(\mathrm{mg} / \mathrm{dl})$. Aldosterone was measured by RIA (17) and ANP was measured as described in our previous report (5). Creatinine and electrolytes in serum and urine were determined using an autoanalyzer (Beckman Astra-8). Data are presented according to CA to clarify the maturational changes of $\mathrm{Ccr}, \mathrm{FENa}$, and plasma aldosterone and ANP concentrations. Results are expressed as mean $\pm \mathrm{SD}$ and analysis of variance was used to determine significant differences between various age groups; $p$ $<0.05$ was considered significant.

\section{RESULTS}

Body wt, serum sodium concentration, and water and sodium balance in the subjects during the study period are shown in Table 2. There was no difference in serum sodium concentration

Table 1. Sequential changes of body wt in infants of five study groups*

\begin{tabular}{ccrcc}
\hline Group & Birth wt (g) & $\begin{array}{r}\text { Nadir wt } \\
\text { (age in d) }\end{array}$ & Wt at 1 wk & Wt at study \\
\hline A & $1295 \pm 278$ & $\begin{array}{r}1166 \pm 290 \\
(5.2 \pm 1.5)\end{array}$ & $1197 \pm 291$ & $1368 \pm 298$ \\
& & $\begin{array}{r}1354 \pm 321 \\
(5.0 \pm 1.1)\end{array}$ & $1386 \pm 323$ & $1515 \pm 310$ \\
B & $1508 \pm 327$ & $1726 \pm 203$ & $1848 \pm 180$ \\
& & & \\
C & $1792 \pm 244 \pm 237$ & $(4.0 \pm 0.9)$ & & \\
& & $1848 \pm 361$ & $1886 \pm 384$ & $2000 \pm 438$ \\
D & $2006 \pm 325$ & $(4.8 \pm 1.5)$ & & \\
& & & \\
E & $3082 \pm 115$ & $2856 \pm 133$ & $3006 \pm 253$ & $3153 \pm 152$ \\
& & $(3.6 \pm 0.8)$ & &
\end{tabular}

* Data was presented as mean $\pm \mathrm{SD}$.

Table 2. Changes of clinical and laboratory parameters in five study groups*

\begin{tabular}{cccc}
\hline Group & $\begin{array}{c}\text { Serum sodium } \\
\text { concentrations } \\
(\mathrm{mEq} / \text { liter })\end{array}$ & $\begin{array}{c}\text { Water } \\
\text { intake/ } \\
\text { output ratio }\end{array}$ & $\begin{array}{c}\text { Sodium } \\
\text { intake/ } \\
\text { output ratio }\end{array}$ \\
\hline A & $135.6 \pm 1.9$ & $1.38 \pm 0.16$ & $4.1 \pm 4.9$ \\
B & $136.8 \pm 1.6$ & $1.50 \pm 0.13$ & $5.9 \pm 4.5$ \\
C & $136.9 \pm 2.6$ & $1.40 \pm 0.17$ & $7.2 \pm 5.7$ \\
D & $137.0 \pm 1.9$ & $1.30 \pm 0.20$ & $4.6 \pm 3.2$ \\
E & $137.4 \pm 1.7$ & $1.40 \pm 0.16$ & $4.2 \pm 2.5$ \\
\hline
\end{tabular}

* Data was presented as mean \pm SD. in each group. None had a hyponatremia less than $130 \mathrm{mEq} /$ liter. Each group had the same water and sodium intake/output ratio. Although sodium intake of all groups was low, ranging between 1.7 and $2.9 \mathrm{mEq} / \mathrm{kg} / \mathrm{d}$, none had a negative sodium balance. There was no difference in these parameters between infants with RDS and LBW infants. Ccr, FENa, plasma aldosterone, and ANP concentrations in each group are shown in Figure 1. Cor of infants less than 36th wk of CA (group A, 0.92 \pm 0.26 , group $B, 0.83 \pm 0.19$, group $C, 0.86 \pm 0.31 \mathrm{ml} / \mathrm{min} / \mathrm{kg}$, respectively) was low when compared with the $\mathrm{Ccr}$ of infants more than 37 th wk of CA (group D, $1.24 \pm 0.08$, group E, 1.87 $\pm 0.66 \mathrm{ml} / \mathrm{min} / \mathrm{kg}$, respectively). FENa of group A $(0.73 \pm$ $0.41 \%$ ) was significantly elevated more than that in group B $(0.25 \pm 0.15 \%)$. Plasma aldosterone concentration of group $A$ $(2868 \pm 1153 \mathrm{pg} / \mathrm{ml})$ was significantly higher than aldosterone levels in groups D and E (group D, $828 \pm 395$, group E, $1004 \pm$ $373 \mathrm{pg} / \mathrm{ml}$, respectively). Plasma ANP concentration was constant in each group, although it was elevated compared with values found in healthy adults $(40 \pm 20 \mathrm{pg} / \mathrm{ml})$. The relationship between FENa and plasma aldosterone levels in all cases is shown

\section{Creatinine clearance}

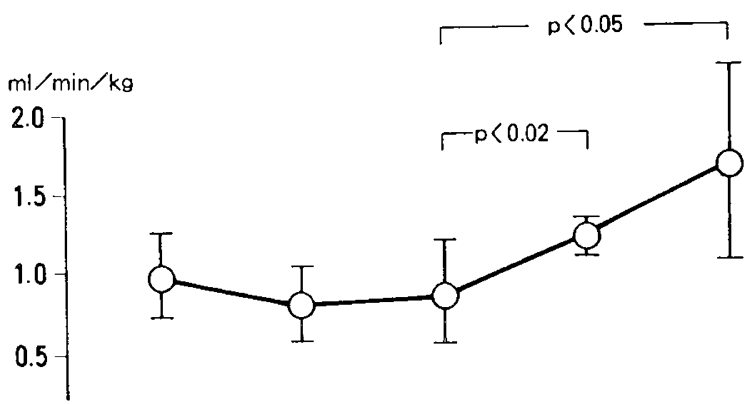

Fractional excretion of Sodium
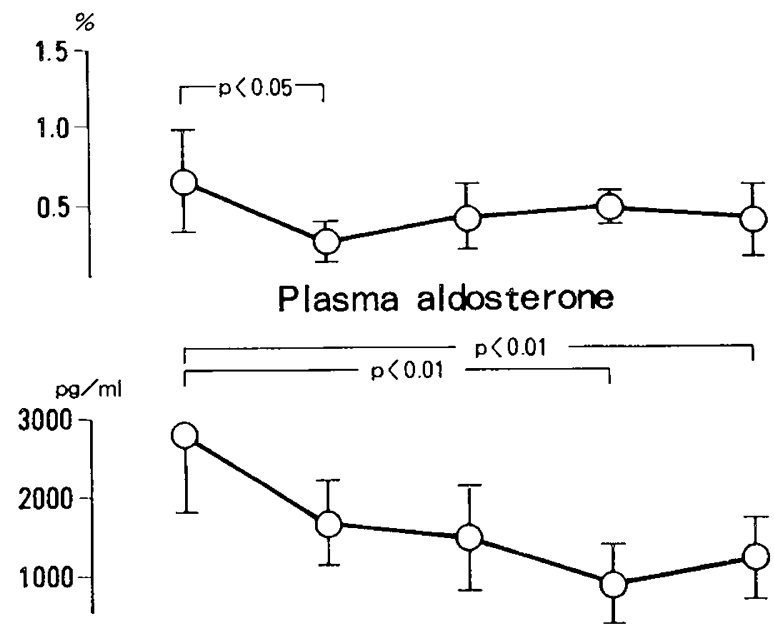

Plasma atrial natriuretic peptide

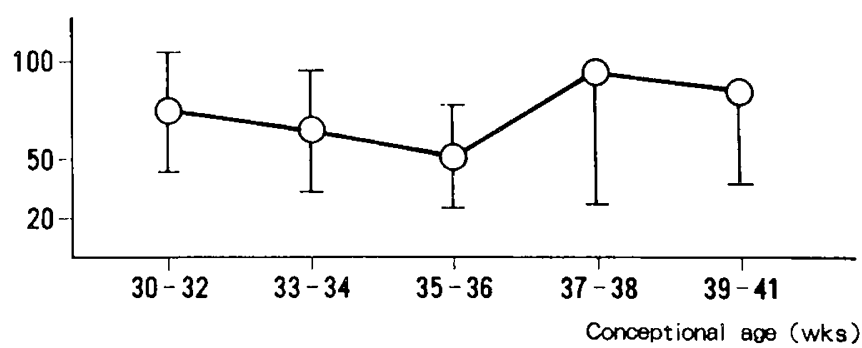

Fig. 1. Creatinine clearance, fractional excretion of sodium, plasma aldosterone, and atrial natriuretic peptide concentrations during the 30 to $4 \mathrm{l}$ wk of conceptional age. Data were shown as mean \pm SD. 
in Figure 2. There was a good negative correlation between these two parameters $(r=-0.515, p<0.01)$. The relationship between Ccr and plasma ANP level in infants less than the 36th wh of $\mathrm{CA}$ is shown in Figure 3. Good correlation was observed between Ccr and plasma ANP level $(r=0.522, p<0.05)$.

\section{DISCUSSION}

This study showed that plasma aldosterone level and FENa in more immature neonates were higher than those in mature neonates. Recent studies have shown that FENa is greater in premature infants than in mature ones and is inversely proportional to the maturity of a neonate $(6,15)$. Premature infants of less than 35 wk of gestation have an obligatory sodium loss, which is believed to be physiologic, resulting from isotonic contraction of body fluid compartments and the disposal of intra- and extracellular fluid solute through the kidney (9). Other studies have indicated that the increased urinary sodium loss in premature infants resulted from deficient proximal and distal tubular reabsorption of sodium $(8,16)$. Although our data on $\mathrm{Ccr}, \mathrm{FENa}$, and plasma aldosterone level in infants of the 30th to $32 \mathrm{nd}$ wk of life were nearly the same as those published previously, FENa and plasma aldosterone levels in infants of more than the 33rd wk of life were lower than those in other reports $(15,16)$. In this study, we found that FENa was correlated with plasma aldosterone level and that there was no case of negative sodium balance or hyponatremia. Although these results show that positive sodium balance could be maintained even in the premature infants, our results contradict the current practice. Sulyok and Varga (6) have found that in low birth wt infants renal salt wasting, subsequent negative sodium balance, and the fall in plasma sodium level induce marked elevation of the

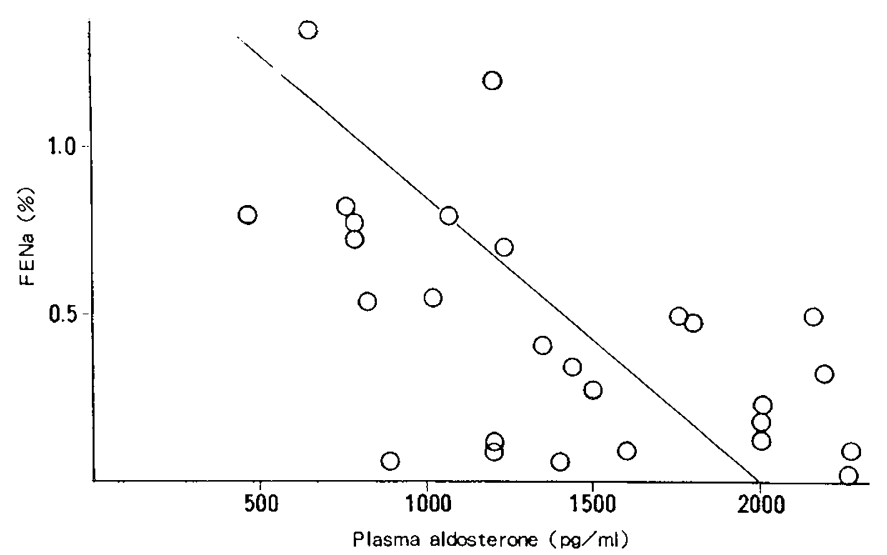

Fig. 2. Relationship between plasma aldosterone concentrations and FENa in all cases $(r=-0.515, p<0.01)$.

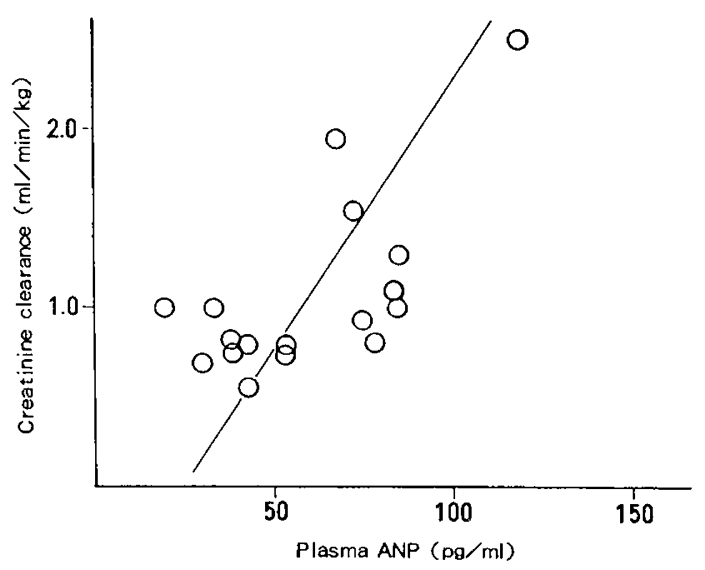

Fig. 3. Relationship between plasma ANP concentrations and $\mathrm{Ccr}$ in the infants of less than $36 \mathrm{wk}$ of conceptional age $(r=0.522, p<0.05)$. activity of the RAAS. In our study, there was no case of negative sodium balance or hyponatremia. We do not know why those premature infants are able to establish positive sodium balance so easily. The characteristics of our nursery protocol may be that sodium and water intakes of premature infants are significantly lower than those found in other nurseries (14), especially during the 1st wk of life. Recent reports have also described that the challenge of salt and water loading leads to a marked natriuretic response and a decrease in the plasma sodium level in premature infants (7). Rodriguez-Soriano et al. (8) demonstrated that the urinary sodium loss observed in very low birthweight infants depends on the incapacity of the distal tubule to cope with the arrival of an increased fractional load of sodium (9). Based on the above observations, we speculate that renal salt wasting in the premature infant may be one of the stimuli for increased aldosterone secretion but that he or she can easily achieve a positive sodium balance under conditions of low sodium intake. For these reasons, we suggest that low dietary sodium may be effective in regulating sodium balance in premature infants.

It is generally considered that GFR does not change appreciably until about the 34th wk of CA, which corresponds to completion of nephrogenesis in the human kidney (10). Although our results were compatible with the above observation, we found that $\mathrm{Ccr}$ in premature infants may be partly regulated by plasma ANP level because creatinine clearance and ANP were related prior to 36 wk CA (Fig. 3). ANP has multiple effects, including inhibition of aldosterone, renin, and vasopressin release, reduction in systolic blood pressure and enhancement of GFR (11). We reported previously that hypersecretion of ANP may play an important part in initiating spontaneous diuresis in sick neonates (5). Tikkanen et al. (12) reported that ANP is released in response to volume distention of the atria in adults. Collectively, these results suggest that ANP may be released in response to volume distention of the extracellular space in premature infants who have a limited GFR. Recently, Shaffer et al. (13) demonstrated that ECV in very low birth wt infants is regulated within a range similar to that in older infants. However, the mechanism of regulation of $\mathrm{ECV}$ in premature infants has not yet been well established. The fall in plasma renin concentrations after saline loading in puppies was greater as they got older, suggesting that the mechanism responsible for the maintenance of plasma renin concentration may be less responsive in the immediate neonatal period (6). In conclusion, we speculate that positive sodium balance established in response to a highly activated RAAS in the premature infant may change ECV and that ANP may compensate for these effects. Further studies are required to clarify the mechanism of water balance in a developing neonate.

\section{REFERENCES}

1. Dillon MJ, Gillin ME, Ryness J, de Swiet M 1976 Plasma renin activity and aldosterone concentration in the human newborn. Arch Dis Child 51:537540

2. Kotchen TA, Strickland AL, Rice TW, Walters DR 1972 A study of the reninangiotensin system in newborn infants. J Pediatr 80:938-946

3. Edelmann CM, Spitzer A 1969 The maturing kidney. A modern view of wellbalanced infants with imbalanced nephrons. J Pediatr 75:509-519

4. Andersson S, Tikkanen I, Pesonen E, Meretoja O, Hynynen M, Fyhrquist F 1987 Atrial natriuretic peptide in patent ductus arteriosus. Pediatr Res 21:396-399

5. Kojima T, Hirata Y, Fukuda Y, Iwase S, Kobayashi Y 1987 Plasma atrial natriuretic peptide and spontaneous diuresis in sick neonates. Arch Dis Child 62:667-670

6. Sulyok E, Varga F 1983 Renal aspects of neonatal sodium homeostasis. Acta Paediatr Hung 24:23-35.

7. Stonestreet BS, Bell EF, Warburton D, Oh W 1983 Renal response in lowbirth-weight neonates. Am J Dis Child 137:215-219

8. Rodriguez-Soriano J, Vallo A, Oliveros R, Castillo G 1983 Renal handling of sodium in premature and full-term neonates: a study using clearance methods during water diuresis. Pediatr Res 17:1013-1016

9. Ross B, Cowett RM, Oh W 1977 Renal functions of low birth weight infants during the first two months of life. Pediatr Res 11:1162-1164

10. Engle WD, Arant BS Jr 1983 Renal handling of beta-2-microglobulin in the human neonate. Kidney Int 24:358-363

11. Nemeh MN, Gilmore JP 1983 Natriuretic activity of human and monkey 
atria Circ Res 53:420-423

12. Tikkanen I, Fyhrquist F, Metsarinne K, Leidenius R 1985 Plasma atrial natriuretic peptide in cardiac disease and during infusion in healthy volunteers. Lancet 2:66-69

13. Shaffer SG, Bradt SK, Meade VM, Hall RT 1987 Extracellular fluid volume changes in very low birth weight infants during first 2 postnatal months. $J$ Pediatr 111:124-128

14. Godard C, Geering J-M, Geering K, Vallolton MB 1979 Plasma renin activity related to sodium balance, renal function and urinary vasopressin in the newborn infant. Pediatr Res 13:742-745

15. Siegel SR, Oh W 1976 Renal function as a marker of human fetal maturation. Acta Paediatr Scand 65:481-485

16. Sulyok E, Nemeth M, Tenyi I, Csaba I, Gyory E, Ertl T, Varga F 1979 Postnatal development of renin-angiotensin-aldosterone system, RAAS, in relation to electrolyte balance in premature infants. Pediatr Res 13:817-820

17. Vetter M, Vetter H, Siegenthaler W 1973 Radioimmunoassay for aldosterone without chromatography. Determination of plasma aldosterone. Acta Endocrinol 74:558-567 